\title{
Organizational Readiness of 3PLs Cold Storage to Implement Blockchain: A Multi-case Study
}

\author{
Anna Johnson \\ Georgia State University \\ Denise McCurdy \\ Georgia State University \\ Daphne Schechter \\ Georgia State University \\ Karen D. Loch \\ Georgia State University
}

The espoused benefits of transformative blockchain technologies appear to be the perfect solution for third party logistics cold storage companies who are facing a myriad of pressing organizational and industry issues. Positive states of organizational readiness are critical for successful implementation. A multi-case study of three $3 \mathrm{rd}$ party logistic cold storage companies examines factors impacting readiness for blockchain, and to what extent size may impact their preparedness. Results indicate that small and medium companies have a relatively low level of readiness to implement blockchain. Due to its robust change management structure, the large company was best positioned to adopt blockchain.

Keywords: organizational readiness, cold chain, blockchain, change management, multi-case study

\section{INTRODUCTION}

The research domain of this study is the third-party logistics (3PL) temperature-controlled warehouse industry. Commonly referred to as "the cold chain," these 3PLs are considered an integral component of the food supply chain (see Figure 1). With over 94 billion pounds of food in temperature-controlled warehouses (Global Cold Chain Alliance, 2018), the cold chain is critical for protecting the quality, temperature, and safety of frozen and refrigerated foods purchased by U.S. consumers. A market set at $\$ 5$ billion and growing, an increasingly sophisticated consumer e-commerce demand, and more stringent government regulations to ensure the protection and integrity of safe and high-quality frozen food products, all collectively contribute to an industry in flux. One major concern is the ability to comprehensively track and trace temperature-controlled goods. The lack of end-to-end visibility has resulted in serious health concerns due to foodborne disease. Forty-eight million people in the U.S. or 1 in 6 get sick, 128,000 are hospitalized, and 3,000 die each year (CDC, 2010, December 15). Economic costs 
of these foodborne illnesses are more than $\$ 50$ billion in the U.S. annually (Mercier, Villeneuve, Mondor, \& Uysal, 2017). Food spoilage and shrinkage contribute to another $\$ 165$ billion in annual losses in the U.S. alone (Gunders, 2012), while global food fraud leads to losses of $\$ 10$ - $\$ 15$ billion annually (Johnson, 2014).

\section{FIGURE 1 3PL IN THE COLD CHAIN}

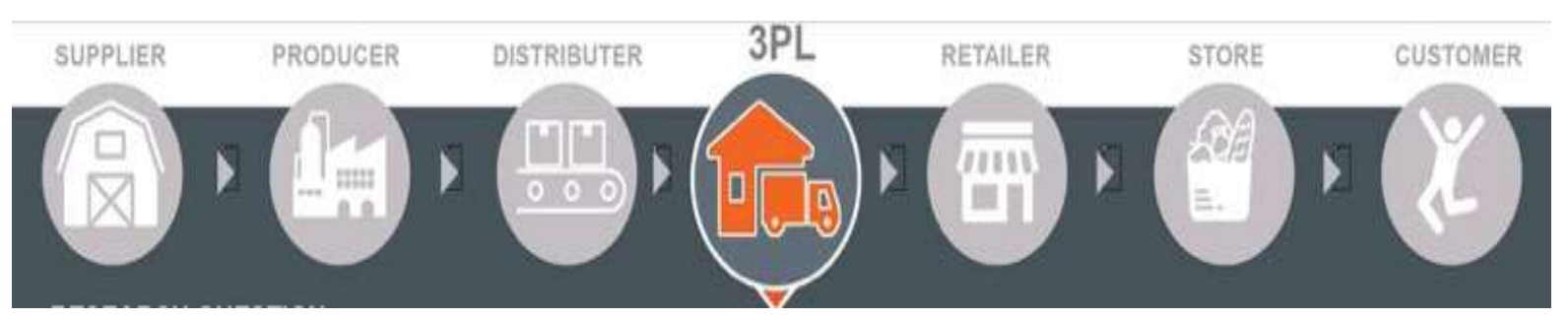

The regulatory environment in the U.S. has responded with new regulation aimed to increase food safety. The Food Safety Modernization Act, or FSMA (U.S. Food \& Drug Administration, 2018), introduced new regulations reflecting a fundamental change in approach to implementing food safety rules. The FSMA passed in 2011 and was fully implemented in 2018. The requirements are stringent for transportation carriers and warehouse providers alike and require preventative control measures to be in place for facilities and carriers.

Given the changing complexion of consumer demand and tighter regulations, there is considerable interest in blockchain technology. Blockchain is a decentralized and distributed ledger that transparently records transactions (Maroufi, Abdolee, \& Tazekand, 2019). Its functionality, apropos the industry, includes the delivery of real-time data such as temperature, expiration dates, product quality, and origins of source, in a continuous, secure fashion by means of a digital ledger that keeps a record of who owns (or is doing) what (Schacklett, 2018). Recorded data cannot be falsified after entry into the blockchain. Using blockchain in 3PL applications, data could therefore be tracked from the food source origin to the consumer, giving visibility to the entire chain. Blockchain's potential benefits for the 3PL industry include a reduction in food fraud, less spoilage, better information sharing, and improved transparency (Yuva, 2017).

Supply chain professionals acknowledge the disruptive nature of blockchain, yet see its coming as inevitable, with the expectation that it can help manage the complexity of global supply chains and positively affect key supply chain management objectives such as cost, quality, speed, dependability, risk reduction, sustainability and flexibility (Kshetri, 2018). While blockchain applications in managing supply chains is still very much in its infancy, there are a handful of blockchain/supply chain proof-ofconcepts, e.g. IBM and Maersk for shipping (IBM, 2018), Walmart for food safety (Hackett, 2017), and Everledger for diamond provenance (Pfannkuche, 2018, September). These proof-of-concepts suggest that blockchain applications will improve supply chain practices, yet it's still the early stages and these firms are the trailblazers.

Academically, while the management of the global supply chain and application of blockchain is a growing field of study (Marucheck, Greis, Mena, \& Cai, 2011), it has been limited to date (Beck, Avital, Rossi, \& Thatcher, 2017). Moreover, the successful adoption of blockchain will require large-scale organizational change within the industry (Beck, Avital, Rossi, \& Thatcher, 2017; Prajogo \& Sojal, 2013). The extent of the required change is significant; Beck et al $(2017$, p.381) refer to the expected change as fundamental, stating that "the implications of creating a reliable, trustworthy distributed record system, or ledger, may be fundamental to how we organize interpersonal and inter-organizational relationships." They call for more academic research to examine the implications of blockchain implementation. 
This study responds to this call with a specific focus on the 3PL cold storage industry and its consideration of the implementation of blockchain. Traditionally, temperature-controlled supply chains are slow to alter their deeply established processes and the rate of technological diffusion within distribution companies has been characterized as slow (Dadzie, Johnston, \& Sadcjev, 1993). Yet the industry is in a state of flux and a blockchain implementation will require significant changes for the cold storage 3PLs, and by extension, the whole supply chain (IBM, 2018; Martin, Nagarajan, Pureswaran, \& Soman, 2018). Consequently, the industry is confronted with the most basic question, are they ready to successfully make the needed changes to implement blockchain?

Extant literature suggests that readiness is a good predictor for successful organizational change (Aremenakis, Harris, \& Mossolder, 1993; Dukes, Loch, \& Dionne, 2019; Scaccia, et al., 2015; Shea, Jacobs, Esserman, Bruce, \& Weiner, 2014; Weiner, 2009), and that size may be an important factor (Dukes, Loch, \& Dionne, 2019; Haveman, 1993; Johnson, 2014; Kacperczyk, 2012). This leads to the two research questions for this study: What is the organizational readiness of temperature-controlled 3PLs to implement blockchain technology? And to what extent does size impact readiness for blockchain? The next section presents the theoretical framework for organizational readiness for change (ORC) and its relationship to future successful implementation of the targeted technology.

\section{THEORETICAL FRAMEWORK}

An organization's readiness for change is positively associated with technological adoption and successful implementation (Hung, Chang, Lin, \& Hsiao, 2014; Kurnia, Choudrie, Mahbubur, \& Alzougool, 2015). The objective of this research study is to examine the structural and psychological factors impacting organizational preparedness for impending, disruptive technological change in the 3PL cold storage industry. Figure 2 presents the theoretical framework for organizational readiness posited by (Weiner, 2009) and modified by (Dukes, Loch, \& Dionne, 2019). Basically, it argues that change valence and informational assessment positively impact the level of organizational readiness for change (ORC). Change valence is the belief that the recipient values the change and there is something in it for them (Aremenakis, Harris, \& Mossolder, 1993; Weiner, 2009). Informational assessment is the perceptions of tasks demands and required resources (e.g. time, people, capital) to effect the change (Weiner, 2009).

Organizational readiness to change (ORC) is comprised of two additional factors, change commitment (is the organization committed to the change in question), and change efficacy (the belief in their collective capability to implement the pending change) (Dukes, Loch, \& Dionne, 2019). Scaccia et al. (2015) proposed what they termed a "practical heuristic" that includes two key factors reflected in Weiner (2009), the extent to which an organization is both willing (i.e. change commitment) and able (i.e. change efficacy) to implement a particular innovation, such as blockchain. Finally, Shea and colleagues (2014) further tested the ORC model and offered evidence in support of the Weiner framework.

The primary contextual factor of interest in this study is organizational size; more specifically to what extent might size impact ORC and subsequent implementation of blockchain. There are two reasons for this. First, the size of the organization could influence the firm's ability to prioritize and resource the project, as well as contribute to the amount of existing expertise with technology to support changes within an organization, all in favor of larger firms.

In the extant research on size, there is a well-established positive relationship between organizational size and a substantial set of organizational outcomes (Josefy, Kuban, Ireland, \& Hitt, 2015). The most common argument is that larger firms are expected to have more slack resources, thereby enhancing their ability to take advantage of opportunities and manage change (Haveman, 1993). The counter argument is that the benefit of additional resources may be reduced as the level of bureaucracy increases, creating a diminishing returns phenomenon.

For small firms, the prevailing belief is that they exhibit less inertia, are therefore more nimble and able to respond more quickly. However, Moulton and Thomas (1993) found that larger firms were more successful in the re-organization that comes with change than smaller firms. Similarly, Kacperczyk (2012) reported that larger firms were more likely to pursue venturing opportunities, suggesting they may 
have a higher ascribed value for making the change and a higher level of commitment to see the change through. Given the expected transformational nature of blockchain which requires a whole ecosystem response (Martin, Nagarajan, Pureswaran, \& Soman, 2018), we posit that the large 3PL firm will ascribe a higher value to the impending change, with a belief in their resources to make the necessary change, both leading to an expressed higher level of readiness than respondents in the medium and small firms.

Second, size implications could be significant for the 3PL cold chain industry in the U.S. due to its unique demographic profile. Of the 250 firms in the industry, the largest three firms control almost $67 \%$ of market share. The overwhelming majority of firms are small, privately held operations. Therefore, the importance of examining organizational readiness in light of size is especially relevant.

\section{FIGURE 2}

\section{THEORETICAL FRAMEWORK OF ORGANIZATIONAL READINESS FOR CHANGE (ORC)}

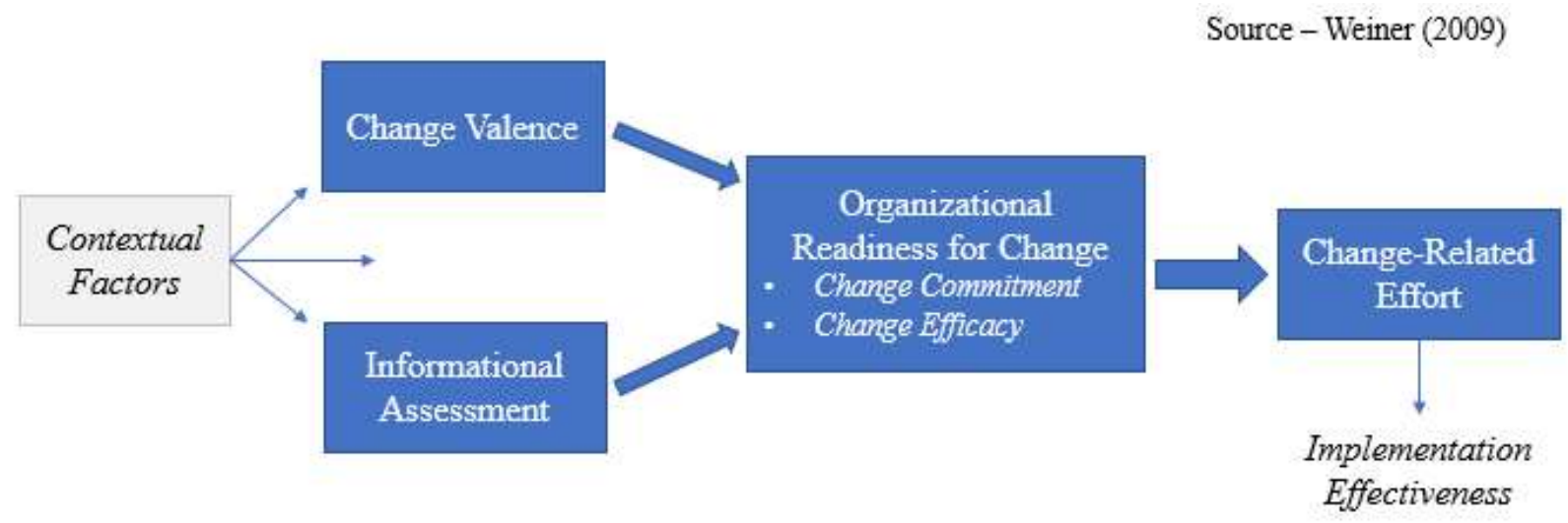

\section{METHODOLOGY}

The study employs a multi-case design including three temperature-controlled 3PL organizations based in the U.S. and differentiated by size. Case criteria were that the firms were reputable in the industry, had regional or national presence in the cold chain, and varied by size. The industry measures size by number of warehouses and cubic feet of warehouse space (See Table 1).

One member of the research team works in the industry and assisted in obtaining agreement from the three 3PLs to identify managers from which to recruit for the interviews. After approximately eight weeks, due to a potential merger and acquisition, the large firm declined to participate in the study. A new large firm was identified and contacted, and they agreed to proceed with the study.

\section{TABLE 1}

COLD CHAIN INDUSTRY SIZE MEASURES

\begin{tabular}{|l|l|l|}
\hline Size & \# Warehouses & Cubic feet \\
\hline Large & $>=50$ & $>500 \mathrm{M}$ \\
\hline Medium & $20-49$ & $100-499 \mathrm{M}$ \\
\hline Small & $1-19$ & $<=99 \mathrm{M}$ \\
\hline
\end{tabular}

CEO-level support at both the large and medium-sized firms facilitated the identification and invitation of senior executive and mid-level managers who had oversight and/or understanding of the main functional areas of the firm and would be involved in decisions and implementation downstream regarding blockchain. There was no presumption that any of the interviewees were experts in blockchain, yet the top and middle manager leaders across functional areas are qualified to assess the readiness of the firm to make such a transformational change. The functional areas included Executive, Operations/Field, 
Sales/Business Development, IT, Human Resources, and Customer Service. The small company identified a senior executive who played a multi-functional role covering sales, operations, and financial responsibility.

The research team conducted semi-structured, one-on-one interviews for the case study. This approach allowed for an in-depth inquiry into each organization's shared psychological and structural state of readiness to implement blockchain in a temperature-controlled 3PL. Before starting, each participant was asked to review and sign a consent form. After consent was received, the interviews were audio recorded and transcribed. Interviews lasted approximately one hour. The researchers completed 13 interviews between May and August 2018. Nine interviews were face-to-face. All interviews were held in the strictest of confidence. Table 2 provides a profile of the interviewees by case, their managerial level, functional area of responsibility, and years in their role and in the industry. The industry is highly concentrated with $67 \%$ of market share held by the top 3 firms. At the same time, of the 250 firms in the industry, more than 246 firms fall in the small category, with less than 99 million cubic feet of storage space. The three cases in this study represent approximately $40 \%$ market share. Consequently, we do not disclose job titles or other information to protect interviewees' confidentiality (See Table 2).

The researchers analyzed data in an interactive process using NVivo 11. An initial set of organizational readiness codes was established from the theoretical framework and new codes were included throughout the analysis. The coding process was checked for inter-rater reliability to ensure consistency. The frequency of each code enabled a convergence of readiness criteria, and the coded excerpts provided deeper context for their specific influences on organizational readiness. Researchers discussed any different interpretations of events and transcripts and resolved issues before coding the entire set of transcripts

Additionally, the research team conducted a deeper analysis into the frequency of terms using NVivo 12, Leximancer and EXCEL. The resulting data supports the high-level themes and sub themes as discussed in the analysis

\section{RESULTS}

\section{Thematic Analysis}

This section reports the four dominant themes found within and across the three case studies. We offer some observations as well on the implications to cold chain 3PLs at the end of each theme section. Table 3 identifies the themes and how they manifest themselves respectively for each case (See Table 3). We labeled the first theme as ORC Contextual Factors. All three cases acknowledged that the implementation of blockchain would require large-scale organizational change and the importance of people and culture in making the change. However, they expressed these factors differently.

Interview 3 (large, mid, operations) described their approach to change as "a very rigorous and methodical manner. We really want to be data driven and fact based much as possible... we want to invite different opinions and perspectives into the conversation. And then make a decision. We're open to change, and you know, how we go about driving change, it's methodical, but at the same time... we try to move quickly as well."

Whereas both the medium and small company placed emphasis on relationships rather than structural systems, and their reticence to change. Interview 5 (medium, mid, operations) described their culture as "I think our culture is people. We have very good culture in our company. . culture is relationships. We not only have relationships with our customer but with our people as well. When we do have new things that come up and it is change, it's a lot easier to, to make that change when you have that relationship with people that you can bring them in and say, Hey, this is something we want to try to do." 
TABLE 2

INTERVIEW PROFILES

\begin{tabular}{|c|c|c|c|c|c|c|}
\hline CASE & COMPANY PROFILE & $\begin{array}{c}\# / \\
\text { SIZE }\end{array}$ & $\begin{array}{c}\text { MGT } \\
\text { LEVEL }\end{array}$ & $\begin{array}{l}\text { FUNC } \\
\text { UNIT }\end{array}$ & $\begin{array}{l}\text { YEARS } \\
\text { IN ROLE }\end{array}$ & $\begin{array}{l}\text { YEARS IN } \\
\text { INDUSTRY }\end{array}$ \\
\hline Large & $\begin{array}{l}\text { \$900MM Revenue (2017) } \\
\text { 7,200 Employees }\end{array}$ & $\begin{array}{l}1-\mathrm{L} \\
2-\mathrm{L} \\
3-\mathrm{L}\end{array}$ & $\begin{array}{l}\text { Top } \\
\text { Top } \\
\text { Mid }\end{array}$ & $\begin{array}{l}1 \\
2 \\
2\end{array}$ & $\begin{array}{l}6 \\
2 \\
5\end{array}$ & $\begin{array}{c}15 \\
2 \\
5\end{array}$ \\
\hline Medium & $\begin{array}{l}\text { \$670MM Revenue (2017) } \\
\text { 3,000 Employees }\end{array}$ & $\begin{array}{l}4-\mathrm{M} \\
5-\mathrm{M} \\
6-\mathrm{M} \\
7-\mathrm{M} \\
8-\mathrm{M} \\
9-\mathrm{M} \\
10-\mathrm{M} \\
11-\mathrm{M} \\
12-\mathrm{M}\end{array}$ & $\begin{array}{l}\text { Top } \\
\text { Mid } \\
\text { Top } \\
\text { Mid } \\
\text { Top } \\
\text { Mid } \\
\text { Top } \\
\text { Mid } \\
\text { Mid }\end{array}$ & $\begin{array}{l}1 \\
2 \\
3 \\
3 \\
4 \\
4 \\
5 \\
5 \\
6\end{array}$ & $\begin{array}{c}.5 \\
4 \\
11 \\
6 \\
1 \\
1 \\
.5 \\
3 \\
2\end{array}$ & $\begin{array}{c}34 \\
22 \\
23 \\
15 \\
18 \\
9 \\
30 \\
3 \\
2\end{array}$ \\
\hline Small & $\begin{array}{l}\text { \$20MM Revenue (2017) } \\
800 \text { Employees }\end{array}$ & $13-\mathrm{S}$ & Top & 1 & 8 & 32 \\
\hline
\end{tabular}

At the same time, Interview 6 (medium, top, sales/biz development) noted "technology changes are typically slow, and you try to find the front runners or the early adopters of the change" as a way to effect change.

Interview 13 (small, top, executive) expressed both these contextual factors that influenced their views on organizational change, particularly related to technology when he expressed the following: "[We are] very service oriented, very focused on the customer, very focused on doing the right thing, very slow to adapt, very slow decision making. Particularly when it comes to technology."

We offer three implications specific to cold storage 3PLs in light of theme 1: Particularly for the medium and small companies, which comprise the largest share of the firms in 3PL industry, there is a need to be more innovative, and open to change. Comprehensive change management practices as evidenced by the large case firm may be a starting point but it will be incumbent on the SME to leverage their relationships strength within their organizations to drive more systemic change processes. In turn, the large companies have the opposite challenge which is to be sure their well-oiled systems remained nimble at the same time. Finally, again for the SMEs, there is a need to create a sense of urgency within the organizations to ensure the company can quickly address new technology and changes, so they won't get left behind.

The second theme that dominated the interviewees' conversation was how they described what compels them to make change. While all three believe that once committed, they will be successful, the large company takes a proactive stance versus the SMEs which are much more reactive. For the large company, it ties adoption of blockchain to strategic commitments and customer benefits, and value to being proactive. Interview 1 (large, top, IT) observed "It's going to drive a level of transparency, both with our customers and our partners and drive accountability in the organization." 
TABLE 3

THEMATIC ANALYSIS - MULTI-CASE COMPARISON OF 3PL COLD STORAGE COMPANIES

\begin{tabular}{|c|c|c|c|}
\hline THEMES & LARGE 3PL & MEDIUM 3PL & SMALL 3PL \\
\hline $\begin{array}{l}\text { (1) ORC } \\
\text { contextual factors }\end{array}$ & $\begin{array}{l}\text { Possesses slack resources } \\
\text { and a "change" mindset. } \\
\text { Developed methodical, } \\
\text { nimble change } \\
\text { management culture. }\end{array}$ & $\begin{array}{l}\text { Placed emphasis on } \\
\text { relational stability of } \\
\text { organizational culture. } \\
\text { Consequently, not as } \\
\text { prepared systemically to } \\
\text { address large-scale } \\
\text { organizational change. } \\
\text { Emphasized they were } \\
\text { slow to adopt new } \\
\text { technology. }\end{array}$ & $\begin{array}{l}\text { Lack of formal change } \\
\text { mechanisms in place for } \\
\text { existing programs, and } \\
\text { limited resources to } \\
\text { commit to change in } \\
\text { general. }\end{array}$ \\
\hline $\begin{array}{l}\text { (2) Drivers to } \\
\text { make } \\
\text { organizational } \\
\text { change: proactive } \\
\text { vs. reactive }\end{array}$ & $\begin{array}{l}\text { Tied adoption of } \\
\text { blockchain to strategic } \\
\text { commitments and } \\
\text { customer benefits, which } \\
\text { strengthens their } \\
\text { commitment and } \\
\text { willingness to make the } \\
\text { changes. } \\
\text { Sees inherent value for the } \\
\text { firm itself, which } \\
\text { heightens their change } \\
\text { valence. }\end{array}$ & $\begin{array}{l}\text { Perceived value of change } \\
\text { dependent on external } \\
\text { forces such as customers' } \\
\text { demands and regulatory } \\
\text { exigencies. Absent these } \\
\text { forces, a reduced change } \\
\text { valence. }\end{array}$ & $\begin{array}{l}\text { Perceived benefits of } \\
\text { blockchain as unproven, } \\
\text { diminishing their } \\
\text { commitment to making } \\
\text { change. }\end{array}$ \\
\hline $\begin{array}{l}\text { (3) Resource } \\
\text { requirements of } \\
\text { 3PLs to implement } \\
\text { blockchain }\end{array}$ & $\begin{array}{l}\text { Funds dedicated resources } \\
\text { for change and project } \\
\text { management. } \\
\text { Believes in their ability to } \\
\text { make a significant change. }\end{array}$ & $\begin{array}{l}\text { Expressed resource } \\
\text { constraints which } \\
\text { dampens other pro- } \\
\text { readiness factors. } \\
\text { Expressed a belief that } \\
\text { could manage the change } \\
\text { if necessary. }\end{array}$ & $\begin{array}{l}\text { Reflected family- } \\
\text { mentality that, with } \\
\text { leadership buy-in, signals } \\
\text { commitment and drives } \\
\text { the belief they can make } \\
\text { the change successfully. } \\
\text { Expressed resource } \\
\text { constraints which } \\
\text { dampens other pro- } \\
\text { readiness factors. }\end{array}$ \\
\hline $\begin{array}{l}\text { (4) Limited } \\
\text { knowledge of } \\
\text { blockchain } \\
\text { influences change } \\
\text { valence }\end{array}$ & $\begin{array}{l}\text { Demonstrated knowledge } \\
\text { and actively engaged in } \\
\text { implementing blockchain } \\
\text { initiatives across } \\
\text { organization. }\end{array}$ & $\begin{array}{l}\text { Demonstrated limited } \\
\text { familiarity with } \\
\text { blockchain. } \\
\text { Demonstrated a cursory } \\
\text { understanding of } \\
\text { blockchain benefits. }\end{array}$ & $\begin{array}{l}\text { Failed to fully understand } \\
\text { the benefits, reducing all } \\
\text { factors of readiness. } \\
\text { Limited perceived need } \\
\text { within the organization } \\
\text { affects the commitment to } \\
\text { change. }\end{array}$ \\
\hline
\end{tabular}


The motivation to change is quite different for the medium and small case, both dependent on external drivers. Interview 9 (medium, mid, IT) sees their motivation is to eliminate risk to their customer and protect their reputation. "I believe the highest priority would be if it's going to eliminate any risk of the consumer being harmed, then I believe that [company] would do it. You wouldn't want to lose business over somebody getting harmed. So that in itself is a return on investment. You're protecting yourself. I say reputation by protecting consumers."

Interview 5 (medium, mid, operations) describe their drivers as customer based: "I think our culture is really driven by the customer's expectations and requirements. If we have a customer that needs a special requirement, IT requirement we would do whatever we need to do to meet that requirement to be a partner with that customer."

Interview13 (small, top, executive) describes their change driver as market forces: "I'd say $90 \%$ of the change here comes from market forces... The senior leadership team here is not sitting in our conference room thinking about all the things that we need to change because we read an article or went to a conference and then decided to do it. Nope. Nope."

Yet, the cold chain is in flux, scrambling to develop comprehensive end-to-end solutions that will benefit supply chain partners and end consumers (U.S. Food \& Drug Administration, 2018) (IBM, 2018) (Hackett, 2017). A hard reality check is now. Beginning September 2019, the 3PLs lost the luxury of time when heavy weight Walmart and its Sam's Club division moved to require suppliers of fresh, leafy greens to implement real-time, end-to-end traceability of products back to the farm using a digital ledger developed by International Business Machines Corp (IBM, 2018). This announcement portends significant implications for the industry. Even small organizations that are not ready will have to move in that direction based on customer demands.

Theme 3 focuses on resources: type, their availability, how they are managed. The large case firm allocates funds for change and project management. The SMEs consider themselves very resource constrained: people, time, and funds. This difference in view seems to manifest itself as an open to change disposition by the large case and a "hunker down" survivor mentality by the other two.

Interview 1 (large, top, executive) describes their resources and how they are leveraged, stating: "We have a strategy execution organization which is both internally and externally focused. Externally, we have customer on-boarding or major customer projects. These organizations are loosely framed as a Program Management Office, but it is generally a change organization."

In contrast, Interview 10 (medium, top, HR) presents a very different tone, sharing that "We don't manage it [change] at all very well. "... we don't push change that change management in general." Interview 6 (medium, top, sales/biz dev) sheds some light on the constrained people resource: "Right, when you have your normal job and then something else comes in, it's hard to make time for that for that new thing."

Finally, Theme 4: Limited knowledge of blockchain shows a strong correspondence to how its implementation was viewed. Interview 1 (large, top, executive) said that "Blockchain to us means primarily an opportunity: whereas the other end, Interview 13 (small, top, executive) stated explicitly "I don't see any reason to implement blockchain because we don't know what it is, and I don't see a benefit."

Significant contrasts between the three cases provide insights into challenges ahead. Blockchain is a platform technology which requires cooperation and collaboration across the cold chain and within the cold chain 3PL industry. Both the large and medium firms agreed that all partners in the industry need to participate to make it successful, noting that individuals within organizations must collectively value the change for the organization to be ready to implement the change and the collective companies within the

cold chain ecosystem must all value the change to share a sense of readiness. The contrasts between the cases are similarly reflected as how they assess their readiness in light of the ORC model's factors.

\section{ORC Model Analysis by Its Factors}

As part of the interview protocol, we also asked the individuals to rate their company's overall readiness to implement blockchain on a scale of one to five, with five being the most ready to implement 
blockchain, and share their rationale for their rating. Table 4 provides a summary assessment for each factor in the ORC model and whether and how it made a positive and/or negative contribution to their readiness to implement blockchain, respectively. Not surprisingly, the large case self-assessed itself as being more ready than the medium firm than did the small firm (See Table 4).

In the end, the critical component of organizational readiness was the area of Change Valence - the level of benefit that determined the perceived level of organizational readiness for each company. We might have expected a strong positive Change Valence for the large firm and a mixed response for the medium. The results are to the contrary, suggesting perhaps a more sophisticated understanding by the large firm of the full challenge of on-boarding all the stakeholders necessarily involved in the implementation of blockchain. The medium company's clear positive may also be influenced by its view of itself as expressed by Interview 7 (medium, mid, sales/biz dev): "we're a family . . once decided, we're all in."

Large Company: The overall assessment of readiness to implement for the large company was a 4 on a scale of 1-5. The Chief Information Officer, who is at the forefront of investigating and piloting blockchain, felt they had leadership commitment, a mature organizational culture, and the project and change management resources to successfully implement blockchain within their four walls. In essence, all components of the ORC model played a valuable role in the readiness to implement disruptive technology.

These sentiments were confirmed by the other interviewees, including representatives from Business Development, HR, and Warehouse General Management. The most significant challenges to readiness included industry data standardization and partners who are willing and able to join forces (Lima, 2018).

TABLE 4

\section{ORC MODEL BY COMPANY SIZE}

\begin{tabular}{|l|c|c|c|}
\hline Stages of ORC Model & Large & Med & Small \\
\hline Context Leadership & $(+)$ & $(+)(-)$ & $(-)(+)$ \\
\hline Change Valence & $(+)(-)$ & $(+)$ & $(-)$ \\
\hline Change Efficacy & $(+)$ & $(+)(-)$ & $(-)(+)$ \\
\hline Info Assessment & $(+)$ & $(+)(-)$ & $(-)$ \\
\hline Change Commitment & $(+)$ & $(-)(+)$ & $(-)(+)$ \\
\hline Change Related Effort & $(+)$ & $(+)(-)$ & $(-)$ \\
\hline ORC Scale Response & 4 & 2.4 & 1 \\
\hline
\end{tabular}

Change Valence is high for the large company. There is a recognition that by continuing to change and being an early adopter of temperature-controlled supply chain innovations, including new technologies, these actions help drive the organization to be more nimble, agile and responsive, as reflective by Interviewee 3: (large, mid, operations): "We are driving a lot of change currently internally with different technologies, different process improvements. We continue to grow and expand. So, there's, there's a lot of change taking place. So... my one concern, would be layering in a change that again, I'm not sure how. ... The caveat to that is we would definitely need the right level of support to implement ... because we do have so much other change going on at the same time."

A distinctive difference, Change Related Effort is a well-oiled machine for the large company. There are three mechanisms dedicated to seeking out and supporting strategic change initiatives: 1) continuous improvement team identifies large-scale opportunities; 2) executive committee of C-suites make strategic decisions; and 3) once decided upon as a strategic priority, the change initiative is handed to 14-person PMO office to execute.

The large company also demonstrated greater insight into the big picture ecosystem and its implications for implementation of blockchain: 
Interview 1: (large, top, executive): "It's not just us, but how ready is the eco-system for blockchain? What I'm intrigued about, especially as I have these conversations, is that we do want to see a community of blockchain users involved, especially in the cold chain, more than any other supply chain users. I see a lot of value in the cold chain to embrace blockchain. So, I'd like to see an emerging cold chain blockchain standard, you know. I'm curious to see after your conversations how the rest of the industry feels about it. And I'm not talking about how we feel about it, but also carriers and customers as well." The role played by the 3PLs in the cold chain was noted as well:

Interview 3: (large, mid, operations): "I think anything that can bring transparency, bridge different operating system barriers ... we're a middle-man as a 3PL. We've got 10 different customers and each of those customers each have 20 to 50 individual customers, so that's a lot of different parties operating on different systems. I think if we had one technology that provides transparency to all those parties, I think that would be a huge benefit."

Medium Company: In contrast, the overall assessment of readiness to implement for the medium company on average was a 2.4 on a scale of 1-5. The senior corporate business executives who had sufficient knowledge of the benefits associated with blockchain and a cursory knowledge of the technology were more confident than the field warehouse team and the information technology team. The field location was concerned with current warehouse projects taking priority for time and resources and the IT organization felt emerging standards, successful implementations as proof-of-concept, and fully demonstrated benefits were necessary before they could fully engage. There were concerns as to whether their resources would be stretched too thin, which is informational assessment in the ORC model.

Interview 5 (medium, mid, operations) observed: "We and every other company that I'm aware of, are under-staffed or under resourced when it comes to IT. I think we, I think our company's, a lot better than a lot of the manufacturing community... I think our queue is, is still a challenge but not to the level that we see with larger companies."

Overall, the medium-sized company had a high change valence and saw the value of change in terms of using blockchain for both a competitive and strategic advantage. The organization's challenge in being ready to implement blockchain and potentially other innovative cold-chain efforts is rooted in the current immaturity of its evolving program management infrastructure, which is more reactive in nature. As such, strategic priorities are not consistently led from a 3 or 5-year strategic plan, but rather efforts for improvements are initiated by customers, employees, functions, etc. The result of this is that despite best efforts, with change valence and change commitment being high, change efficacy, information assessment, change related effort will prevent the organization from being agile and staying ahead of the industry.

The long-term heritage and pride of being a culture of "we are like a family" for the medium firm could be preventing the organization from developing essential processes to enable fluid and successful change. Fear of becoming "too corporate" underlies the potential barriers to successfully implementing large-scale beneficial initiatives. Hence the score of 2.4 appears to be in line with the desire to change but the inability to easily support change effort.

Change Valence is high for the medium company. There is a recognition that being early adopters of temperature-controlled supply chain innovations including new technologies helps drive the organization's competitive advantage.

Interview 4 (medium, top, executive) remarked: “... I don't want to come into something that we don't know, but at the same time we wanted to give it a shot. We wanted to make sure that it works. We're trying, ... we wanted to be the first in implementing blockchain. That should be our goal. Now, how extensively we are going to implement it is up for the negotiation... But, we definitely wanted to just boast to the public that we['re] ready and that we have the knowledge and now let's discuss how you want to do it."

The medium-sized company makes centralized decisions but does not centralize dedicated program and change resources for innovative and potentially disruptive change. The work force bandwidth is an issue. Interview 10 (medium, top, HR) offers an explanation: 
"We don't have project managers. [Employees] still have their 50 hour a week job and customer first. Get the truck out. That's always the first priority. And if you don't have those people doing the things they need to do to make the change work, you're not going to be successful at it. And as you go down [hierarchies], change would be less and less of a priority."

Small Company: The overall assessment of readiness to implement for the small company on was a one (1) on a scale of 1-5, with the biggest challenges being slowness of the industry to change overall and a conservative leadership. Interview 13 (small, top, executive) stated: "We're...very service oriented, very focused on the customer, very focused on doing the right thing, very slow to adopt, very slow [in our] decision making... particularly when it comes to technology."

Similar to the medium-sized company, the small company has an informal change process with an unstructured approach to innovative changes, with the exception of safety concerns which follows a more structured mandate. The value of implementing blockchain is low for the small company. Until the benefits and costs are clearly understood, the small company has reservations to introduce this level of change unless required to do so by external forces (customers).

The same interviewee goes on to say: "I don't see any reason to implement blockchain because a) we don't know what it is, and b) I don't see a benefit."

This company believes they are efficient once committing to change, perhaps because of its small size, but similar to the medium-size company, the pressure to "do more with less" impedes instituting systematic change efforts. Finding human resources in the current environment is a struggle, as the small company is in a growth mode. Increasing productivity is a key driver for their change programs. This combination of challenging implementations from previous years, coupled with the company's growth and human capital shortages, explicates the mixed assessment for change efficacy. In addition, there is a reluctance to use outside resources, i.e. paid consultants, as "outsiders" are not viewed as part of the company-family and would not share small company values.

For the small company, change effort, the amount of activities and resources the company may invest in change, is informal with no mechanisms in place for most new projects for programs. Instead, employees are encouraged to attend conferences and, if applicable, share their views in group conversations. The implementation of a company-wide warehouse management system did require a significant amount of activity from most employees. This implementation was considered complex and challenged the small company, in part because of the lack of change experience.

Interview 13 (small, top, executive) reflected on their most recent change experience: "Any change like that is going to be painful because you don't know what you don't know... we just thought we asked the right questions and we did... but there were a whole set of others we didn't even think about."

\section{Visual Case Comparison Analysis}

Figure 3 depicts the top fifteen ranked concepts by each case respectively as extracted from the NVivo analysis. Both the small and medium cases were internally focused on their constrained resources, particularly as it related to their workforce, both supply and availability of their workforce to take on tasks demands as would be required by blockchain implementation.

However, the medium-size firm does show a progression in the expansion of their assessment to include the role of managers and awareness of their customer. This is consistent with their remarks that change comes about as a result of external demand, e.g. customer driven. In contrast, the large company's picture depicts a more mature view of a large-scale implementation as would be required by blockchain. All three interviews for the large case espoused their systematic change process approach to managing change, and the engagement of multiple project managers. While they acknowledged that blockchain implementation would be a big change, the relative weight depicted appears to be in balance with their confidence of their ability to be successful (See Figure 3). 


\section{DISCUSSION}

Failure at change management has been found to reflect a lack of organizational readiness (Kotter, 1996). Our results in the 3PL cold storage industry suggest that 3PL readiness for blockchain positively impacts preparation efforts. Organizational readiness for change was found to impacted by managerial beliefs in the value of such changes (i.e. change valence), the resources available to implement change (i.e. informational assessment) and change efficacy (i.e. the confidence in their ability to effectuate the change). This answers our second question "to what extent does size impact readiness for blockchain?" Size appears to matter as evidenced by the comparison of these three 3PL cases and suggests that organizational size is likely important in understanding the extent of change readiness for implementing new technologies. Finally, the raw data illustrate a lack of overall preparedness for blockchain, with the smaller the firm, the more marked is their lack of readiness to implement blockchain. For example, the small case response is consistently in a more negative manner to all stages of the readiness model in contrast to the medium-size and large-size 3PL (see Table 4). From a policy perspective, government programs should be tailored to enhance the information available and the expected benefits to SMEs on the use of blockchain technology, and there is clearly a need for the 3PL industry to self-educate and prepare for what is undoubtedly part of their future. A lack of preparation by 3PLs will entail significant costs to the ecosystem.

\section{FIGURE 3}

\section{CASE COMPARISON: ILLUSTRATION OF RANKED CONCEPTS BY CASE}

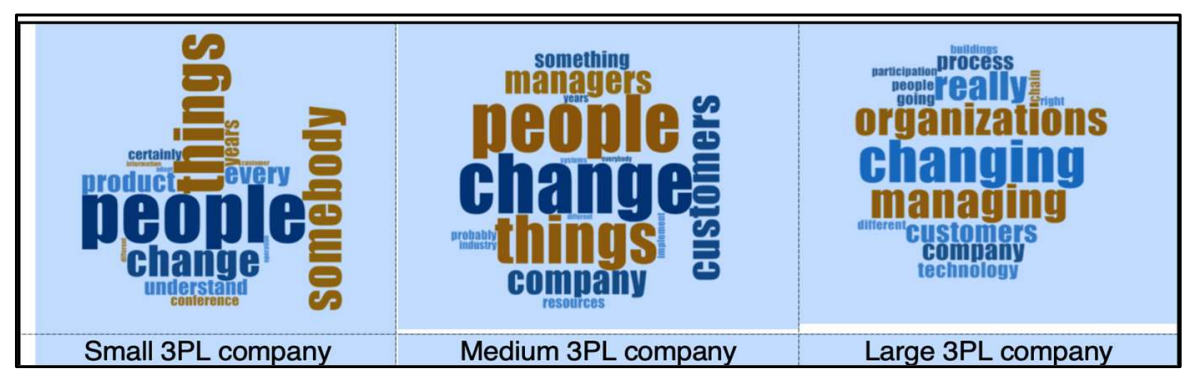

This multiple case study makes two important theoretical contributions. First, we extend the application of the ORC framework to a previously under-represented area of concern within supply chain, the temperature controlled Third Party Logistics industry, and the application of an emerging technology in blockchain. Scholars have previously applied the ORC framework in a single case, healthcare setting and by relating the framework to the cold chain ecosystem, we can offer a rich understanding of the interplay among the readiness constructs and change motivators that underpin organizational readiness at both a firm and industry level.

The analysis illuminated the varied readiness states to implement blockchain due to the inability to dedicate centralized change and program management resources to change. Rigorous and structured change management processes are important at the individual firm level; however, we also found that coopetition and standards are essential for the ecosystem to contribute as a whole to a platform technology change. Much like a chain of links, a platform technology change at the industry level will only be as successful as the weakest link in the chain. The large 3PL did appear to have a level of understanding of the eco-system implications of blockchain that were not part of the reference frame for the small 3PL in particular.

Second, this study provides an answer to the state of readiness of temperature-controlled 3PLs to implement blockchain technology. Holistic food traceability within the cold chain is challenging with multiple parties involved in getting the food from the farm to the table. This inability to track products results in food fraud, spoilage, pilferage, and food safety and quality issues. As blockchain emerges as the solution to food traceability, the readiness of temperature-controlled 3PLs to implement blockchain is of 
critical importance to the entire food supply chain. We took the temperature of the cold chain 3PL industry and we found that the industry is hot for blockchain but lukewarm to cold when it comes to the state of readiness to implement the technology change.

This study makes a number of contributions to practice. First, since blockchain is a new and evolving technology, the study provides a standard description of blockchain to create consistency among the industry firms. Cold chain 3PLs can benefit by unifying their understanding of blockchain as it will break down silos of information and contribute to industry alignment.

Second, this study offers advice to small and mid-sized firms that seek to enhance their readiness to implement change by illuminating the underlying factors that contribute to organizational readiness and concrete examples may be undertaken to improve their readiness respectively. For example, a structured change management approach that is imbedded within all levels of the organization influences the perceived readiness of the large firm. Any cold chain 3PL that needs to make technology changes might consider a focus on building a more robust change management approach in order to be prepared to implement change.

Third, this study highlights one of many challenges for the 3PL cold storage industry overall: the increasing disintermediation in the supply chain, regulatory changes increasing need for action, and a disruptive technology that is in its early stages yet will require co-dependency of players for successful implementation. Institutionalized change management processes and slack resources as suggested in the literature do appear to be advantageous for the large 3PL firm over its smaller counterparts. However, blockchain is different from past experiences with implementing new technologies such as RFID, which is a "within" organizational change. While there was some acknowledgement that blockchain requires all parties in the cold chain ecosystem to collaborate for a successful implementation, there remained a more parochial expression of competition and competitive advantage as a "we" and "they" rather than a "us".

The ORC framework provided a systematic way to assess the level of readiness of cold chain 3PLs to implement blockchain technology. An exploratory case comparison of three 3PL firms, it did provide support for the extant literature arguing that the degree of readiness is a good predictor for success of implementation (Kotter, 1996).

\section{LIMITATIONS AND FUTURE RESEARCH}

The study has several limitations. While the managerial level of respondents allowed for proper line of sight into the respective case to assess its readiness for blockchain, the limited number of interviews at both the large and small firms makes it more difficult to comprehensively understand their differences and limits our ability to extrapolate and generalize to other 3PLs.Second, there is limited awareness and understanding of blockchain, particularly for the small and medium case firms. Since the participants in the study did not understand the platform technology structure of blockchain, there was a reluctance to share information related to their internal processes for fear they would be giving away competitive advantage by allowing visibility to their firm's proprietary processes. The interview questions were designed to elicit responses to provide information that could be used to assess readiness constructs however, additional insight might be gained if participants had a better understanding of the co-opetition necessary for blockchain to be successful

While these three cases shed important insights into the industry at large and specifically to these three firms with regards to organizational readiness to implement blockchain and the role the size of the organization may play, generalizability should be made with caution. A single interviewee spoke on behalf of the small firm. This is somewhat a function of the small firm where attention to the pressing day-to-day matters were a higher priority. The participation of a senior executive however infers their interest in being informed. The small firm interviewee served in multiple functions within the organization over time with the firm and was in a position to provide broad insight in technology, business development, operations, and human resources. The richness of the data provided by the individual warranted inclusion in the study. 
Based on the interviewees' comments, there will need to be a shift in how they self-identify vis-à-vis others in the existing supply chain. This is clearly an area for future research to better understand the process of required organizational transformation and the factors that may be most influential to help 3PLs make these changes. Information sharing across companies is a requisite for blockchain. Another area ripe for research is the establishment of standards and the role for the cold chain 3PLs to work together in a proactive manner rather than the reactive behavior to change that seems to be part of their traditional modus operandi.

\section{REFERENCES}

Aremenakis, A., Harris, S., \& Mossolder, K. (1993). Creating readiness for organizational change. Human Relations, 46(6), 681-703.

Beck, R., Avital, M., Rossi, M., \& Thatcher, J. (2017). Blockchain technology in business and information systems research. Business and Information Systems Engineering, 59(6), 381-384.

Centers for Disease Control. (2010, December 15). CDC Reports: 1 in 6 get sick from foodborne illnesses each year. Atlanta, GA, USA. Retrieved from https://www.cdc.gov/media/pressrel/2010/r101215.html

Dadzie, K., Johnston, W., \& Sadcjev, H. (1993). Organizational characteristics and the adoption of innovative warehouse automation technologies. Proceedings of the 1993 Academy of Marketing Science Annual Conference (p.581). Miami Beach, FL: Springer International Publishing.

Davenport, T.H. (1993). Process innovation: Reengineering work through information technology. Harvard Business Press.

Dukes, M., Loch, K., \& Dionne, S. (2019). Carrier readiness for autonomous vehicles: The impact of organizational size on change readiness in the U.S. trucking industry. Proceedings of the International Conference of Small Business (forthcoming). Cairo, Egypt.

Gübelin Gem Lab. (2018, September). Provenance Proof Blockchain to be rolled out and open to the entire industry by February 2019. Lucerne, France. Retrieved from https://www.gubelingemlab.com/en/news/detail/provenance-proof-blockchain-to-be-rolled-outand-open-to-the-entire-industry-by-february-2019-154

Global Cold Chain Alliance. (2018, February 6). Cold Chain Logistics: Protecting your food, contributing to your community. Retrieved from https://www.gcca.org/resources/blogs/coldconnection/cold-chain-logistics-protecting-your-food-contributing-your.

Gunders, D. (2012). Wasted: How America is losing up to 40 percent of its food from farm to fork to landfill. Natural Resources Defense Council.

Hackett, R. (2017, August 22). Why big business is racing to build blockchains. Fortune. Retrieved from http://fortune.com/2017/08/22/bitcoin-ethereum-blockchain-cryptocurrency

Haveman, H. (1993). Organizational size and change: Diversification in the savings and loan industry after deregulation. Administrative Science Quarterly, pp. 20-50.

Hung, W-H., Chang, L-M., Lin, C-P., \& Hsiao, C-H. (2014). E-readiness of website acceptance and implementation in SMEs. Computers in Human Behavior, 40, 44-55.

IBM. (2018, August 9). Maersk and IBM Introduce TradeLens Blockchain Shipping Solution. Armonk, New York, United States. Retrieved from https://newsroom.ibm.com/2018-08-09-Maersk-andIBM-Introduce-TradeLens-Blockchain-Shipping-Solution

Johnson, R. (2014). Food fraud and economically motivated adulteration of food and food ingredients. Washington, DC: Congressional Research Service.

Josefy, M., Kuban, S., Ireland, D., \& Hitt, M. (2015). All things great and small: Organizational size, boundaries of the firm, and a changing environment. The Academy of Management Annals, 9(1), 715-802.

Kacperczyk, A. (2012). Opportunity structures in established firms: Entrepreneurship versus intrapreneurship in mutual funds. Administrative Science Quarterly, 57(3), 484-521.

Kotter, J. (1996). Leading Change. Boston: Harvard Business School Press. 
Kshetri, N. (2018). Blockchain's roles in meeting key supply chain management objectives. International Journal of Information Management, 39, 80-89.

Kurnia, S., Choudrie, J., Mahbubur, R.M., \& Alzougool, B. (2015). E-commerce technology adoption: A Malaysian grocery SME retail sector study. Journal of Business Research, 68(9), 1906-1918.

Lima, C. (2018). Developing Open and Interoperable DLTVBlockchain Standards [Standards]. Computer, 51(11), 106-111. doi:10.1109/MC.2018.2876184

Martin, A., Nagarajan, S., Pureswaran, V., \& Soman, S. (2018, November). Building your blockchain advantage: Fresh insights on how to create value, scale fast, and open new markets. Retrieved from https://www.ibm.com/downloads/cas/KLA16WMZ

Maroufi, M., Abdolee, R., \& Tazekand, B.M. (2019). On the convergence of blockchain and internet of things (iot) technologies. arXiv preprint arXiv:1904.01936.

Marucheck, A., Greis, N., Mena, C., \& Cai, L. (2011). Product safety and security in the global supply chain: Issues, challenges and research opportunities. Journal of Operations Managment, 29(7-8), 707-720.

Mercier, S., Villeneuve, S., Mondor, M., \& Uysal, I. (2017). Time-temperature managment along the food cold chain: A review of recent developments. Comprehensive Rviews in Food Science and Food Safety, 16(4), 647-667.

Moulton, W., \& Thomas, H. (1993). Bankruptcy as a deliberate strategy: Theoretical considerations and empirical evidence. Stretegic Management Journal, 14(2), 125-135.

Pfannkuche, P. (2018, September). Provenance Proof Blockchain to be rolled out and open to the entire industry by February 2019 [Press release]. Retrieved from https://www.everledger.io/pdfs/Pressrelease-Gubelin-Everledger-Provenance-Proof-blockchain-to-be-rolled-out.pdf

Prajogo, D., \& Sojal, A. (2013). Supply chain professionals: A study of competencies, use of technologies, and future challenges. International Journal of Operations \& Production Management, 33(11-12), 1532-1554.

Scaccia, J., Cook, B., Lamont, A., Wandersman, A., Castellow, J., Katz, J., \& Beidas, R. (2015). A practical implementation science heuristic for organizational readiness: $\mathrm{R}=\mathrm{MC} 2$. Journal of Community Psychology, 43(4), 484-501.

Schacklett, M. (2018, March 19). IoT gains a foothold in food supply chains. Food Logistics. Retrieved from https://www.foodlogistics.com/technology/article/20993391/iot-gains-a-foothold-in-foodsupply-chains

Shea, C., Jacobs, S., Esserman, D., Bruce, K., \& Weiner, B. (2014). Organizational readiness for implementing change: A psychometric assessment of a new measure. Implementation Science, 9(7). Retrieved from https://implementationscience. biomedcentral.com/articles/10.1186/17485908-9-7

U.S. Food \& Drug Administration. (2018, May 16). FDA Food Safety Modernization Act (FMSA).

Retrieved from https://www.fda.gov/food/guidance-regulation-food-and-dietarysupplements/food-safety-modernization-act-fsma

Weiner, B. (2009). A theory of organizational readieness for change. Implementation Science, 4.

Retrieved from https://implementationscience.biomedcentral.com/articles/10.1186/1748-5908-467

Yuva, J. (2017). Blockchain: Next of Food Supply Chain Menu. Food Logistics, 192, 22-28.

60 Journal of Strategic Innovation and Sustainability Vol. 15(6) 2020 